\title{
Informal and hidden curricula in ethics teaching at Zagreb School of Medicine English program
}

\author{
Pranav Sharma ${ }^{1} \cdot$ Sanja Babic- Bosanac ${ }^{2}$. \\ Ana Borovecki ${ }^{3}$ - Davor Jezek ${ }^{4}$
}

Published online: 7 October 2016

C Springer International Publishing AG 2016

\begin{abstract}
Development of medical students' professional ethical values can be influenced by the quality of role models and the experiences they encounter during their education. Essays from all enrolled 6-year students in Medical Studies in English Program at School of Medicine, University of Zagreb in the academic year 2014/2015 were anonymised and analysed according to acknowledged quantitative analysis methods. Three major themes occurred when reading students' essays: physician patient relationship, inter professional relationships among physicians and nurses and teacher student relationship. Students suggested a need for mandatory workshops on communicational skills for physicians and placing the ethics course earlier in the curriculum. The essays of the students show the importance of hidden curriculum in ethics teaching and how role models play an
\end{abstract}

Ana Borovecki

abor@mef.hr

Pranav Sharma

pranav1sharma@gmail.com

Sanja Babic- Bosanac

sbabic@snz.hr

Davor Jezek

davor.jezek@mef.hr

1 School of Medicine, University of Zagreb, Zagreb, Croatia

2 Department of Medical Sociology and Health Economics, University of Zagreb, School of Medicine, Andrija Stampar School of Public Health Medical School, Zagreb, Croatia

3 Department of Social Medicine and the Organization of Healthcare, University of Zagreb, School of Medicine, Andrija Stampar School of Public Health Medical School, Rockefellerova 4, 10 000 Zagreb, Croatia

4 School of Medicine, Department of Histology and Embryology, University of Zagreb, Zagreb, Croatia 
important part in the learning experience when it comes to professional ethical values and norms.

Keywords Ethics $\cdot$ Education/programs $\cdot$ Medicine $\cdot$ Hidden curriculum

\section{Introduction}

Ethical competencies are part of medical professionalism and thus teaching medical ethics is one of the components of medical education worldwide (Monrouxe 2010). Medical students experience ethics learning in a wide variety of formats, not just through curriculum. In the clinical years ethics learning has an opportunistic nature. Development of students' professional ethical values can be influenced by the quality of role models and the experiences they encounter thus highlighting the reality of hidden curriculum. Professional modelling even unassumingly performed can be powerful in transmitting values and attitudes to medical students and "ethical erosion" correlates with students' observations of unethical behaviours (Kenny et al. 2003).

In the academic year 2003, University of Zagreb School of Medicine introduced a new 12 semester (6-year) Medical Studies in English (MSE) Program. Graduates of the program are granted a diploma conferring the professional title of Doctor of Medicine (MD). This program is entirely instructed in English language, and is also designed so as to meet both American (USMLE) and European Union standards. It usually enrols up to 50 students per year and on average has from 20 to 50 students per each year of the study depending on the year of the study. In 2015 University of Zagreb School of Medicine was awarded the Certificate for Quality in Programme Internationalisation - CeQuint, for Integrated undergraduate and graduate university studies in medicine (in English language). Medical ethics is taught in the 6th year of the study, although a 2 -h lecture and $4 \mathrm{~h}$ of seminars dedicated to introduction into medical ethics are taken by students in the first year of the study as part of the course Introduction to Medicine and Social Medicine. Medical ethics course consists of $6 \mathrm{~h}$ of lectures and $24 \mathrm{~h}$ of seminars and 10 tutorials. The course has interdisciplinary approach and philosophers, lawyers, theologians and experts from different medical specialties come to teach students about ethical issues in medicine web page Medical Studies in English, http://mse. mef.unizg.hr/. The course is a replica of the course started in 1990-ties for Croatian undergraduate medical students as a part of the curriculum in the 6th year of the study (Zurak et al. 1999). In the academic year 2013/14 medical ethics course in the Medical Studies in English Program was slightly modified and the new form of examination was introduced. Instead of multiple choice tests and an oral examination the written students' essays were introduced. The essays were written on the topic "What are for me the main ethical issues that I have observed as a student in medical practice?" Students were also asked to compare ethical issues encountered in Croatia to those experienced in their own countries or other countries since students are obliged to do a clinical practice during their summer breaks usually away from Croatian healthcare institutions in order to gain international experience. They were encouraged to describe examples and situation that had ethical issues. The aim of the introduction of the new form of examination 
was twofold. The application of ethical issues to everyday experience of medical practice was tested together with the comprehension of ethical issues and theories discussed in the classes.

When the essays came in something interesting unfolded in their narrative. Patterns were starting to emerge that clearly dealt with models of behaviour that students experienced in Croatian clinical settings which were often quite apart from the ethical behaviour that they were thought in ethics classes. There was a hidden curriculum pattern emerging that prompted us to rethink our approach to ethics education. This paper explores what we found out by reading these essays.

\section{Method}

\section{Participants and procedure}

Twenty essays from 20 6-year (final year) medical students in the academic year $2013 / 2014$ (this is a total number of students enrolled in this year) were analysed using qualitative methodology. The students were all enrolled in the University of Zagreb School of Medicine English programme. Students came from the following countries: France, Sweden, Canada, UK, US, Macedonia, Kenya, Germany, Austria, South Africa and Croatia. The essays were written as a part of final exam for the subject Medical Ethics which is taught in the 6th (final year) of medical education. The essays were written on the topic "What are for me the main ethical issues that I have observed as a student in medical practice?" Each essay focused on personal experience of the students. Each individual expressed her/his personal opinions regarding issues as well as her/his interpretations of personal experiences. The permission for the research was obtained from ethics committee of the School of Medicine, University of Zagreb. The informed consent was obtained from students to use their essays. Students were given assurance verbally and in writing that their essays would not be read by anyone other than two authors (PS and $\mathrm{AB}$ ) and that the identity would not be disclosed to anyone.

\section{Measure}

The text was analysed by two persons using qualitative analysis methods. Each essay was analysed to look for trends and patterns that featured various ethical issues. The process that was used involved 3 main steps. Firstly a "naïve" reading was conducted. This entailed an open minded view of each essay to provide a sense about the text, as well as a direction of the overall context of the text. The impression formed during the first reading was then used in the second step in which the "structural analysis" of the text was conducted. Here a coding technique was employed in which a word or a short phrase that symbolically assigns a summative or salient attribute was looked for. Coding provided a detailed analysis of the text in order to explain the parts and validate or invalidate the initial understanding gained from the initial reading. The text was divided into meaning units that were then condensed, abstracted and structured into sub-themes and themes which were based upon various ethical issues. A "comprehensive 
understanding" was then developed based on the data from the initial naïve reading as well as the structural analysis (Saldaña 2009).

\section{Results}

There were 20 essays in total submitted by medical students. We have selected for our analysis only 17 because those essays brought personal experiences and cases in their analysis. The other three essays dealt with ethical issues in general. One dealt with ethics in research analysing examples of Tuskegee syphilis study and the case of cells from Henrietta Lacks. The other concentrated on ethical issues in access to healthcare in Canada in more general terms. The third dealt with issues related to relationships between physicians and pharmaceutical companies.

There major themes described in students' essays were: physician-patient relationship, inter professional relationships among physicians and nurses and teacher student relationship (Table 1).

Table 1 Ethical issues encountered by 6- year medical students during their medical training at Zagreb School of Medicine during Medical Studies in English Program

Physician patient relationship

Decisions regarding treatment

Problems surrounding informed consent (paternalism)

Communication

$\begin{array}{lr}\text { Inadequate communication } & 8\end{array}$

Breaking patient confidentiality 2

Delivering bad news $\quad 2$

Adolescent confidentiality 1

Disclosing medical errors $\quad 1$

Deliberate lies and deception in context of healthcare $\quad 1$

Lack of compassion 2

Professional duties

Disrespectful treatment of patients/family $\quad 4$

Discrimination (age, gender, race) 2

Physician- physician interaction

$\begin{array}{ll}\text { Inappropriate communication among physicians } & 4\end{array}$

Disrespectful remarks harassment of nurses $\quad 1$

Teacher student relationship

$\begin{array}{lr}\text { Learning on patients over their objections or without consent } & 6\end{array}$

$\begin{array}{ll}\text { Asked to compromise my own ethical standards } & 1\end{array}$

$\begin{array}{ll}\text { Not being fully involve in training } & 4\end{array}$

$\begin{array}{ll}\text { Harassments of students } & 3\end{array}$

$\begin{array}{ll}\text { Cheating on the exams by Croatian students } & 1\end{array}$ 


\section{Physician patient relationship}

The majority of the essays dealt with issues related to paternalist approach to patients in Croatia in comparison to other countries and students provided examples of it.

P10: "The doctor's relationship with patient has been rather paternalistic and outdated at times. Patients' prognoses have been discussed at their bedside usually on the rude assumption that the patients do not understand English."

Second issue discussed was the issue of informed consent and how this was not properly taken in Croatia.

P17: "I have been witness to some doctors obtaining informed consent from the patients for certain procedures, even surgical ones, after the procedure has been done"

P10: "Sometimes the treatment options discussed were not options but rather stern orders which stole the persons 'right to choice'.."

Third issue addressed was the issues of communicational practices of Croatian physicians.

P3: "The difference that I have seen in the different institutions in Canada and Croatia and the patient-doctor relationship, primarily is in the way that doctors speak with their patient what information they give and how they do so.. Many times I feel like doctors talk above their patients and sadly, look down on them..."

P4: "Doctor $\mathrm{X}$ was typing on the computer finishing the date-input concerning pervious patient. The patient was with a simple hand gesture shown that she should sit down and no further greeting were extended towards the patient. After 5 min Dr. X turned towards the patient looking for the patient file and started to talk. He muttered that her results had been received and indeed she has cancer.... He continued in his opinion it would be best to start chemotherapy immediately.. the women... replied that she would like to come back the flowing day.. she was especially concerned with the fact that she might lose her hair... Dr $\mathrm{X}$ gave the patient bewildered look and answered that she will loss her hair regardless of her starting today or tomorrow with the treatment and that instead of dealing with the hair loss this way she should rather spend her time looking for a wig.."

Other issues discussed and observed in practice in Croatia were age discrimination, lack of professionalism (improper jokes about patients), lack of compassion for patients, respect for privacy during intimate examination of patient, lack of confidentiality, ICU ethics, ethical issues related to HIV infection, informing family about death of a patient, abortion. 
P1: "a 25 year old woman presented with a 4 weeks old pregnancy and was eligible to undergo a medical treatment to terminate the pregnancy what she opted for... after explaining the procedure to her and taking her consent... he turned to the students, notably my colleague and me commenting the patient's marital status implying her abortion comes as a consequence of her irresponsible behaviour and premarital sex which should not be practiced..."

P2: "according to our literature and the American Medical Association patient's families should be noted immediately after the patient's death by telephone and should immediately come to the hospital...this was not the experience we had when my parental grandfather suffered myocardial infarction in Zagreb and passed ways some days after in a hospital... we came for a visits.. after a minute of awkward silence the nurse said she would return in a moment... we waited for 30 min... we were escorted to a small office to wait for on-call physician... after another 30 min the doctor finally came and let us know that our grandfather went into cardiac arrest and could not be resuscitated..."

P9:"on the ward I heard that he was known to tell highly inappropriate jokes to pancreatic cancer patients about their illness and time left to live."

Not only bad but also good examples were observed in Croatian medical practice by the students.

P8: "I felt that the average physician-patient relationship was not of equal quality as in Sweden.. but I still observed some great relationships in Zagreb and concluded that many doctors self-learn this part of medicine as they grow as doctors.."

P9: "...two accidental parallel cases on gastroenterology.. that I encountered through internal medicine of how optimism and happiness can be a great tool and is something that should be encouraged in physician-patient relationship.."

P11:"I have experienced the doctor involving patients in decision-making, patients bringing up some concerns and then at the end they come to mutual agreement.."

P11: "Some doctors talk to their patients as if they are friends, they have a good communication, they make them feel comfortable and inform them on every single test that is being done and why..."

P13: "Despite a pervading negative cultural opinion towards the Roma I have witnessed an equal level of care offered to Roma patients.."

As possible remedy for the existing problems one student suggested a need for mandatory workshops on communicational skills for physicians.

Moreover students have witnessed some bad examples in other counties where they did their summer practice: 
P12: "When pressed for why the father does not believe his son need the procedure, the father reveals that he does not trust the physician's reason for the surgery and believes that the physician wants to make money from the procedure.." (USA)

\section{Inter-professional relationships}

Students also described some not acceptable practices that they observed during their clinical practice in Croatia that took place between healthcare professionals: poor communication, improper behaviour among colleagues, poor teamwork, and sexual harassment of nurses by physicians.

P10: “.. interns have little or no responsibilities during their rotation which leave majority of the burden to residents, their hard work then presented to consultants on a platter... the lack of team work is evident... it is unfortunate norm in this society."

P11: "On some wards, there is a dysfunctional relationship between doctors and nurses, residents and interns. Some doctors disrespect young doctors and other colleagues and make their life miserable because they can. Some residents go through hell just because a senior doctor has complexes of some kind..."

P11: "I have also encountered nurses being constantly bullied by sexual comments jokes etc. Some of them felt very uncomfortable but it is not like they could say something to their superior. They know if they say something they will probably get in trouble and doctors know that nurses won't say anything.."

Students also described good examples:

P11: "There are doctors that are loved by younger doctors because they have this attitude that is approachable, which allows them to ask for help if needed..."

\section{Teacher student relationships}

Students found relationship among teacher and students to differ in Croatia and other countries. In Croatia they found a hierarchical system being in place.

P2: "In Croatia there is a strict hierarchical system in place... it is expected and students know about it and quickly accept it... most physicians expect and insist upon being address by a title. ...most of the students do not feel comfortable approaching such high-ranking professor...in Sweden there is less of it, everyone works together as a team.. teaching is more collaborative approach...". 
When it comes to teacher student relationship students complained about the lack of involvement in everyday clinical practice and that they often felt as the odd man out as a nuisance.

P5: “.. the Croatian student has more of an observer type status... he has not been given responsibilities.. French medical student is given responsibilities... he has patient to take care of..."

P5: "..humiliation is one way of teaching in this country which is still present in front of the medical staff, during presentations of patients, in front of the patient during grand ward, being asked questions and not knowing the answer..."

P8: "we notice how doctors are very busy with patients and we don't understand ourselves how they can have time for group of 5 students while struggling to cope with patients. I think this is the reason students have received a poor reputation around wards for just being in the way and not being helpful.."

They also reported patients being examined without consent by students.

P9: "The patient was a 90 year old female, with severe diabetes and its comorbidities- practically blind with hearing disabilities and had both legs amputated. She was newly in the ward for newly diagnosed neoplastic process in the rectum and recto-vaginal fistula. The doctor asked for volunteer among students to palpate with his finger the fistula located in the vagina through the rectum. Not only did I consider the behaviour by the physician as unethical but also the reaction of number (6-7) of students and the lack of their consideration for the patient appalled me..."

P13: "On one particular occasion a physician was so overwhelmed by his desire to teach us, his students, how to do digital rectal exam that he put the patient in awkward position where there are 10 students observing and 4 students consecutively performing this examination. At the end of this, the patient was sobbing under her covers..."

Some students reported improper behaviour of some teachers towards female medical students that boarded on sexual harassment.

P10: "Sexual discrimination....is usually directed at young, attractive medical students by noticing their physician appearance, a compliment or joke- but it has no place in the workplace..."

Students also presented good examples of teacher student relationship.

P14: "There is both an untold and told rule that we're part of a team, something which is re-emphasized continuously in a country like Croatia where even medical students are referred as colleague.." 
P11: “.. the atmosphere in a... hospital is much more relaxed... as a student I felt more welcome ..."

P8: "For me as a medical student it was not only an educative experience to sit and listen to this discussion, but I noticed how the patient felt much more comfortable and developed a strong relationship with physician."

Students also addressed the issue of ethics teaching in general and proposed placing ethics earlier in the curriculum somewhere at the beginning of the clinical practice courses in the 3rd year of the study. Another student suggested using trained actors as patents in order to improve students' communicational skills.

\section{Discussion}

The types of ethical issues encountered by students in our research show considerable degree of similarity with those encountered by students in research done by Kaladijan et al. and Caldicott et al. Decisions regarding treatment especially informed consent practices, communication, professional behaviour and student specific issues seem to be prominent (Kaladjian et al. 2012; Caldicott and Faber-Langendoen 2005). However, in our case when it comes to decision-making students concentrated predominantly on the issues of paternalism in decision-making. The experiences of our students can be corroborated by other research on informed consent practices and patient autonomy in Croatia (Vucemilo et al. 2013; Vucemilo and Borovecki 2014). For this reason greater importance should be dedicated to patient autonomy issues in medical education in Croatia (Murgic et al. 2015).

The essays of the students also show hidden curriculum can covey completely opposite messages than the official one. On one hand formally we try to convey to medical students the importance of altruism, accountability, excellence, duty, honour, integrity, respect for others, and a commitment to lifelong learning. On the other hand our students experience abuse of power, bias, sexual harassment, breach of confidentiality, arrogance and witness pretty undesirable behaviours towards patients. The hidden curriculum can have a negative impact on ethical development of medical students as they progress through medical school (Johnston and Mok 2015). Hren et al.did a study on Croatian medical students at Zagreb School of Medicine trying to test Kollebrg's ideas on cognitive-developmental approach. They observed in their research regression from post conventional schema to maintaining the norms schema among medical students during their education (Hren et al. 2011).

Our students also reported mistreatment. Literature on subject of mistreatment of university students is showing that mistreatment of university students was observed to be most common during medical studies. The largest student group that reported immoral and unethical treatment, in a study done by Rautio et al. in Finland, were female students at the Faculty of Medicine (Rautio et al. 2005).

So what can be done in order to avoid the existing discrepancy between formal and hidden curricula at Zagreb School of Medicine when it comes to teaching ethics?

The students provided us with some answers in their essays worth implementing in our opinion. They suggested that ethics teaching should be moved from 6 th year to the 
3rd year of medical studies thus moving ethics education to preclinical years. The preclinical medical education stage is especially important for moulding students' moral orientation because at the age 18-22 years students exhibit the most flexibility in their learning ability. A proper medical education at this stage will prepare them for the complex clinical situations they will encounter (Lin et al. 2012).

Moreover, students suggested a need for mandatory workshops on communicational skills for physicians, also very important in our opinion. Moreover, the environment in the teaching hospitals should be improved making those involved in the teaching to have more time for students. Personnel on wards in teaching hospitals should be made aware how important is their interpersonal behaviour and their behaviour towards patients for teaching clinical, communicational skills and ethical values. Maybe additional workshop on this matter and team building exercise would not be in vain.

Zagreb School of Medicine has recently introduced a new course for students. It is a longitudinal course that last for 6 years and provides medical students with good basis in communicational skills and practices, clinical skills and adequate etiquette which should be observed at all times on the wards. Hopefully, in the future cases like those described by the students in this paper will disappear from hospital wards in Croatia.

\section{References}

Caldicott, C.V., and K. Faber-Langendoen. 2005. Deception, discrimination and fear of reprisal: lessons in ethics from third-year medical students. Academic Medicine 80: 866-73.

Hren, D., M. Marusic, and A. Marusic. 2011. Regression of moral reasoning during medical education: combined design study to evaluate the effect of clinical study years. PLOS ONE 6(3): e17406.

Johnston, C., and J. Mok. 2015. How medical students learn ethics: an online log of their leraning experiences. Journal of Medical Ethics 41: 854-858.

Kaladjian, L.C., M.E. Rosenbaum, L. Shinkunas, et al. 2012. Through student's eyes: ethical and professional issues identified by third-year medical student during clerkship. Journal of Medical Ethics 38: 130-132.

Kenny, N.P., K.V. Mann, and H. MacLeod. 2003. Role modelling in physicians' professional formation: reconsidering an essential but untapped educational strategy. Academic Medicine 78: 1203-10.

Lin, C.S., K.I. Tsou, S.H. Cho, et al. 2012. Is medical students' moral orientation changeable after preclinical medical education? Journal of Medical Ethics 38: 168-173.

Medical Studies in English. Zagreb School of Medicine. Retrieved December 27th 2015. http://mse. mef.unizg.hr/.

Monrouxe, L.V. 2010. Identity, identification and medical education: why should we care? Medical Education 44: 40-9.

Murgic, L., P.C. Hebert, S. Sovic, and G. Pavlekovic. 2015. Paternalism and autonomy: views of patients and providers in atransitional(post-communist) country. BMC Medical Ethics 16: 65.

Rautio, A., V. Sunnari, M. Nuutinen, and M. Laitala. 2005. Mistreatment of university students most common during medical studies. BMC Medical Education 5: 36.

Saldaña, J. 2009. The coding manual for qualitative researchers. London: SAGE Publications, Incorporated.

Vucemilo, L., and A. Borovecki. 2014. Informed consent in Croatia. A work in progress. Cambridge Quarterly of Healthcare Ethics 3: 356-60.

Vucemilo, L., M. Curkovic, M. Milosevic, J. Mustajbegovic, and A. Borovecki. 2013. Are physician-patient communication practices slowly changing in Croatia? - a cross-sectional questionnaire study. Croatian Medical Journal 2: 185-91.

Zurak, N., D. Derezic, and G. Pavlekovic. 1999. Students' opinions on the medical ethics course in the medical school curriculum. Journal of Medical Ethics 25: 61-62. 